\title{
Efficacy of interventions that include diet, aerobic and resistance training components for type 2 diabetes prevention: a systematic review with meta-analysis
}

Elroy J Aguiar ${ }^{1,2}$, Philip J Morgan ${ }^{1,3}$, Clare E Collins ${ }^{1,4}$, Ronald C Plotnikoff ${ }^{1,3}$ and Robin Callister ${ }^{1,2^{*}}$

\begin{abstract}
Current recommendations for the prevention of type 2 diabetes advise modification of diet and exercise behaviors including both aerobic and resistance training. However, the efficacy of multi-component interventions involving a combination of these three components has not been established. The aims of this review were to systematically review and meta-analyze the evidence on multi-component (diet + aerobic exercise + resistance training) lifestyle interventions for type 2 diabetes prevention. Eight electronic databases (Medline, Embase, SportDiscus, Web of Science, CINAHL, Informit health collection, Cochrane library and Scopus) were searched up to June 2013. Eligible studies 1) recruited prediabetic adults or individuals at risk of type 2 diabetes; 2) conducted diet and exercise [including both physical activity/aerobic and resistance training] programs; and 3) reported weight and plasma glucose outcomes. In total, 23 articles from eight studies were eligible including five randomized controlled trials, one quasi-experimental, one two-group comparison and one single-group pre-post study. Four studies had a low risk of bias (score $\geq 6 / 10$ ). Median intervention length was 12 months (range 4-48 months) with a follow-up of 18 months (range 6.5 - 48 months). The diet and exercise interventions varied slightly in terms of their specific prescriptions. Meta-analysis favored interventions over controls for weight loss $(-3.79 \mathrm{~kg}[-6.13,-1.46 ; 95 \% \mathrm{Cl}]$, $Z=3.19, P=0.001)$ and fasting plasma glucose $\left(-0.13 \mathrm{mmol}^{-1} \mathrm{~L}^{-1}[-0.24,-0.02 ; 95 \% \mathrm{Cl}], \mathrm{Z}=2.42, \mathrm{P}=0.02\right)$. Diabetes incidence was only reported in two studies, with reductions of $58 \%$ and $56 \%$ versus control groups. In summary, multi-component lifestyle type 2 diabetes prevention interventions that include diet and both aerobic and resistance exercise training are modestly effective in inducing weight loss and improving impaired fasting glucose, glucose tolerance, dietary and exercise outcomes in at risk and prediabetic adult populations. These results support the current exercise guidelines for the inclusion of resistance training in type 2 diabetes prevention, however there remains a need for more rigorous studies, with long-term follow-up evaluating program efficacy, muscular fitness outcomes, diabetes incidence and risk reduction.
\end{abstract}

Keywords: Prediabetes, Diabetes, Obesity, Lifestyle, Weight loss, Diet, Exercise, Resistance training

\footnotetext{
* Correspondence: Robin.Callister@newcastle.edu.au

'Priority Research Centre for Physical Activity and Nutrition, University of

Newcastle, Callaghan Campus, University Dr, Callaghan, NSW 2308, Australia

${ }^{2}$ School of Biomedical Sciences and Pharmacy, Faculty of Health, University of

Newcastle, Callaghan Campus, University Dr, Callaghan, NSW 2308, Australia

Full list of author information is available at the end of the article
} 


\section{Introduction}

Type 2 diabetes mellitus (T2DM) is one of the fastest growing non-communicable diseases worldwide [1,2]. Recommendations for T2DM prevention include maintaining a healthy weight, consuming a healthy diet, and participation in exercise. Most T2DM prevention programs have recommended aerobic (cardio-respiratory) activities [3] with strong evidence supporting this approach. Largescale prevention studies such as the Diabetes Prevention Program (DPP) [4] reported reductions in T2DM incidence of up to 58\% [5] and improvements in risk factors such as weight and insulin sensitivity.

More recently, resistance training (RT) has been included in guidelines for T2DM based on evidence established over the last decade, which demonstrates benefits from RT including improved fasting plasma glucose (FPG) [6-11], glycosylated haemoglobin $\left(\mathrm{HbA}_{1 \mathrm{C}}\right)$ [8-16], insulin sensitivity $[8,14]$ and the maintenance of fat free mass during energy restriction for weight loss $[17,18]$. Current guidelines for T2DM prevention and management $[3,19]$ recommend at least $150 \mathrm{~min}$ per week of moderate-vigorous aerobic activity and an additional two (ideally three) RT sessions per week (at least $60 \mathrm{~min}$ ). Studies have reported that the combination of aerobic plus RT has additive benefits on glucose control $[16,20,21]$ and can achieve greater reductions in T2DM incidence [22,23] than the use of a single exercise modality. However, multi-component (diet + aerobic exercise $+\mathrm{RT}$ ) lifestyle interventions have the potential to become excessively burdensome, which could compromise program adherence. Further, the long-term efficacy of multi-component programs remains unclear.

Therefore, the aim of this systematic review was to summarize the evidence of the efficacy of lifestyle interventions that include diet + aerobic exercise $+\mathrm{RT}$ components in at risk or prediabetic populations. Specifically, this review assesses the effects of these interventions on weight change, glucose regulation, and diet and exercise outcomes. A secondary aim was to conduct a meta-analysis of the impact on weight and FPG. Addressing these aims is necessary to validate the evidence supporting current dietary and exercise guidelines for T2DM prevention.

\section{Methods}

The Preferred Reporting Items for Systematic reviews and Meta-Analyses (PRISMA) statement [24] guided the conduct and reporting of this review.

\section{Information sources}

A systematic literature search was conducted using electronic databases (Medline, Embase, SportDiscus, ISI Web of Knowledge [Web of Science], CINAHL, Informit health collection, Cochrane library, Scopus) until June
2013. No limit was placed on publication date. The search strategy included the use of terms in three broad categories: (i) population; (ii) intervention; and (iii) study type. The search terms list included the following items: pre-diabetic OR prediabetic OR pre-diabetes OR prediabetes OR glucose intolerance OR impaired glucose tolerance OR impaired fasting glucose AND exercise OR resistance training OR weight lifting OR aerobic training OR diet OR lifestyle OR life-style AND randomized controlled trial OR randomised controlled trial OR controlled clinical trial OR randomized OR randomised OR randomly OR trial OR groups OR intervention OR study OR program. Reference lists of included studies and key reviews in the area were also manually searched for additional articles.

\section{Eligibility criteria}

Studies were included if they: (i) targeted T2DM prevention in at risk or prediabetic adults ( $>18$ years); (ii) employed a lifestyle diet and exercise intervention including both aerobic and RT; and (iii) reported weight and plasma glucose. All study designs were considered. Studies were excluded if they: (i) recruited individuals with T2DM; (ii) recruited individuals diagnosed with severe medical problems unrelated to prediabetes or from other special populations (e.g., mental illness, polycystic ovarian syndrome, gestational diabetes); (iii) used drug therapy or surgical procedures as part of the intervention.

\section{Study selection}

After duplicate deletion, one author (EA) screened all articles based on title and abstracts for preliminary inclusion; then screened remaining articles by full text based on inclusion criteria. In cases where there was uncertainty, a second reviewer (RC) assessed the article and consensus was reached by discussion.

\section{Data collection process and data items}

Characteristics and results of studies were extracted by one author (EA). Studies with multiple published articles were reported as a single group. For meta-analyses, final mean and standard deviation (SD) or change in mean and SD were extracted for weight $(\mathrm{kg})$ and FPG (mmol. $\mathrm{L}^{-1}$ ). In some studies, the required statistics for metaanalysis were not reported. If available, other statistics e.g., 95\% confidence interval (CI) or standard error (SE) were converted to the required form according to the calculations outlined in the Cochrane Handbook for Systematic Reviews of Interventions (Section 7.7 and 16.1.3.2) [25]. 


\section{Risk of bias in individual studies}

Risk of bias for individual studies was assessed for randomized trials using a 10-item quality checklist adapted from the Consolidated Standards of Reporting Trials (CONSORT) statement [26]. The 10-item scale and explanations of the scoring for each item are available (see Additional file 1). Each item was scored with a ' 1 ' for 'yes' or '0' for 'no'. Inter-rater reliability was calculated on a dichotomous scale using percentage agreement and Cohen's $\kappa$. Un-weighted sum totals were calculated for each study. Based on a dichotomy used in recent reviews $[27,28]$ studies were classified as having a low (score $\geq 6$ ) or high risk of bias (score $\leq 5)$. Two authors (EA and RC) assessed the risk of bias in the individual studies that met the inclusion criteria. In the case of disagreement, discussion took place until consensus was reached.

\section{Summary measures and synthesis of results}

The primary outcomes for the review were the between group difference in means for weight $(\mathrm{kg})$ and FPG $\left(\mathrm{mmol} . \mathrm{L}^{-1}\right)$. Secondary outcomes included 2-h oral glucose tolerance test (OGTT, mmol.L ${ }^{-1}$ ) and $\mathrm{HbA}_{1 \mathrm{C}} \%$, dietary outcomes (e.g., macronutrient composition) and exercise outcomes (e.g., physical activity, aerobic and muscular fitness). Meta-analyses for weight and FPG were conducted for eligible randomized controlled trials (RCT). Results were pooled in separate meta-analyses using RevMan 5.1.4 for Mac OS X. All data were continuous and reported on the same scale for weight $(\mathrm{kg})$ and FPG (mmol. $\left.\mathrm{L}^{-1}\right)$. Heterogeneity of studies included for meta-analysis was determined using $\mathrm{Chi}^{2}$ and $\mathrm{I}^{2}$ statistics. A significance level of $\mathrm{P}<0.10$ for the $\mathrm{Chi}^{2}$ test and an $\mathrm{I}^{2}$ greater than $50 \%$ indicated substantial heterogeneity [24]. The fixed-effects model was used for homogenous samples and the random-effects model was used where heterogeneity was present. The aggregate result was calculated as the weighted mean difference (WMD) between interventions and controls. Metaanalysis was deemed inappropriate for variables where results from fewer than three studies were available.

\section{Results}

\section{Study selection}

After duplicate deletion, 8048 original articles were identified (Figure 1). After title/abstract screening and further full-text screening, 23 articles arising from eight studies were deemed eligible. Of these, four studies were eligible for meta-analysis of weight and five studies for meta-analysis of FPG.

\section{Study characteristics}

Of the eight included studies, two were conducted in the United States [29-32], one in New Zealand [33,34], Austria [35], the Netherlands [36-40], Australia [41],
Finland [42-49] and the United Kingdom [50,51]. Characteristics of these studies are presented in Additional file 2. Five studies [29-31,33,34,36-40,42-51] used an RCT design, with the remaining studies employing quasi-experimental [41] two-group comparison [35] or single-group pre-post designs [32]. Three studies specifically recruited impaired glucose tolerance (IGT) participants [33,42-51], one study recruited impaired fasting glucose (IFG) participants [35], one study recruited both IGT and IFG participants [32], and three studies recruited an 'at risk for prediabetes' population [29-31,36-41]. The collective sample size of the studies at baseline was 1050 participants, with females comprising $62 \%$ of the sample. Mean $( \pm$ SD) age was $54.5 \pm$ 9.7 years. Five studies [33-40,42-51] used an individual face-to-face mode as the primary means of intervention delivery, while three studies [29-32,41] used a group face-to-face mode. All studies conducted supervised individual and group exercise programs for some period of the intervention (Additional file 2). One study had an initial one-week period with a physical therapist and thereafter the exercise program was selfdriven [32]. Most studies used gym facilities, however one study used an unsupervised home-based RT component for one of their intervention groups [41].

Median intervention length was 12 months (range 4-48 months) with a follow-up of 18 months (range 6.5 - 48 months). Details of the diet and exercise interventions are reported in Additional file 2. Briefly, participants were advised to perform aerobic exercise for an average of $5.0 \pm 1.5$ days. wk $^{-1}$ (mean \pm SD), with an average duration of $157.5 \pm 44.4 \mathrm{~min}_{\mathrm{wk}} \mathrm{w}^{-1}$ and to perform $\mathrm{RT}$ for an average of $2.3 \pm 0.7$ days. $\mathrm{wk}^{-1}$ for an average duration of $90.0 \pm 24.5 \mathrm{~min} . \mathrm{wk}^{-1}$. Five studies prescribed energy restriction for weight loss and seven studies prescribed a specific dietary macronutrient profile.

\section{Risk of bias within studies}

The 10-item risk of bias analysis results for seven of the eight included studies are presented in Table 1. Bersoux et al. [32] was excluded as it was a non-randomized trial. Inter-rater reliability demonstrated a high initial level of agreement across all risk of bias items (percentage agreement $100 \%$, Cohen's $\mathrm{k}=1$ ), with no further discussion required. In total, three studies were classified as having a high risk of bias (score $\leq 5)[35,41,50,51]$ and four studies as having a low risk of bias (score $\geq 6$ ) $[29,30,33,34,36-40,42-49]$.

\section{Results of included studies}

A summary of results is presented in Additional file 3. A brief description of results is presented below. Results are presented as change in mean from baseline to end of 
intervention or as pre-post intervention. Follow-up results (where available) are presented in Additional file 3.

\section{Weight change}

Seven of the eight studies reported a reduction in weight $(\mathrm{kg})$ for the intervention group at the end of their respective interventions and four of the five RCTs reported significant weight loss for the intervention group compared to controls (Additional file 3). The largest weight loss $(-8.2 \pm 5.7 \mathrm{~kg})$ was reported by Villareal et al. [29-31] after 26 weeks of intervention. The Finnish DPS [42-49] and SLIM studies [36-40] reported a reduction in weight for the intervention compared to controls (INT $-3.5 \pm 5.1$ vs $\mathrm{CON}-0.9 \pm 5.4 \mathrm{~kg}, \mathrm{P}<0.001$ and INT $-1.08 \pm 4.30$ vs CON $0.16 \pm 4.91 \mathrm{~kg}, \mathrm{P}=0.045$, respectively) after three years, demonstrating that smallmoderate long-term weight loss is achievable in this population.

\section{Glucose regulation}

FPG was reported in all eight studies (Additional file 3). Only two of the five RCTs reported significant differences between the intervention and control groups. Villareal et al. [29-31] reported the intervention group had a reduction in FPG at 26 weeks whereas the control group increased $(\mathrm{P}<0.05)$. In the SLIM study [36-40], FPG increased in both groups after three years relative to baseline, however the difference between groups was significant $(\mathrm{P}=0.04)$. Payne et al. [41] and Burtscher et al. [35] reported significant within group pre-post reductions in FPG ( $\mathrm{P}<0.001$ and $\mathrm{P}<0.05$, respectively) at 12 months. Two-hour OGTT was reported in five studies (Additional file 3). Villareal et al. [29-31] reported a reduction in 2-h OGTT at 26 weeks for the intervention group whereas the control group increased $(\mathrm{P}<0.05)$. Bersoux et al. [32] and Payne et al. [41] reported within group pre-post reductions $(\mathrm{P}=0.04$ and $\mathrm{P}=0.011$, respectively) at 6 and 12 months,

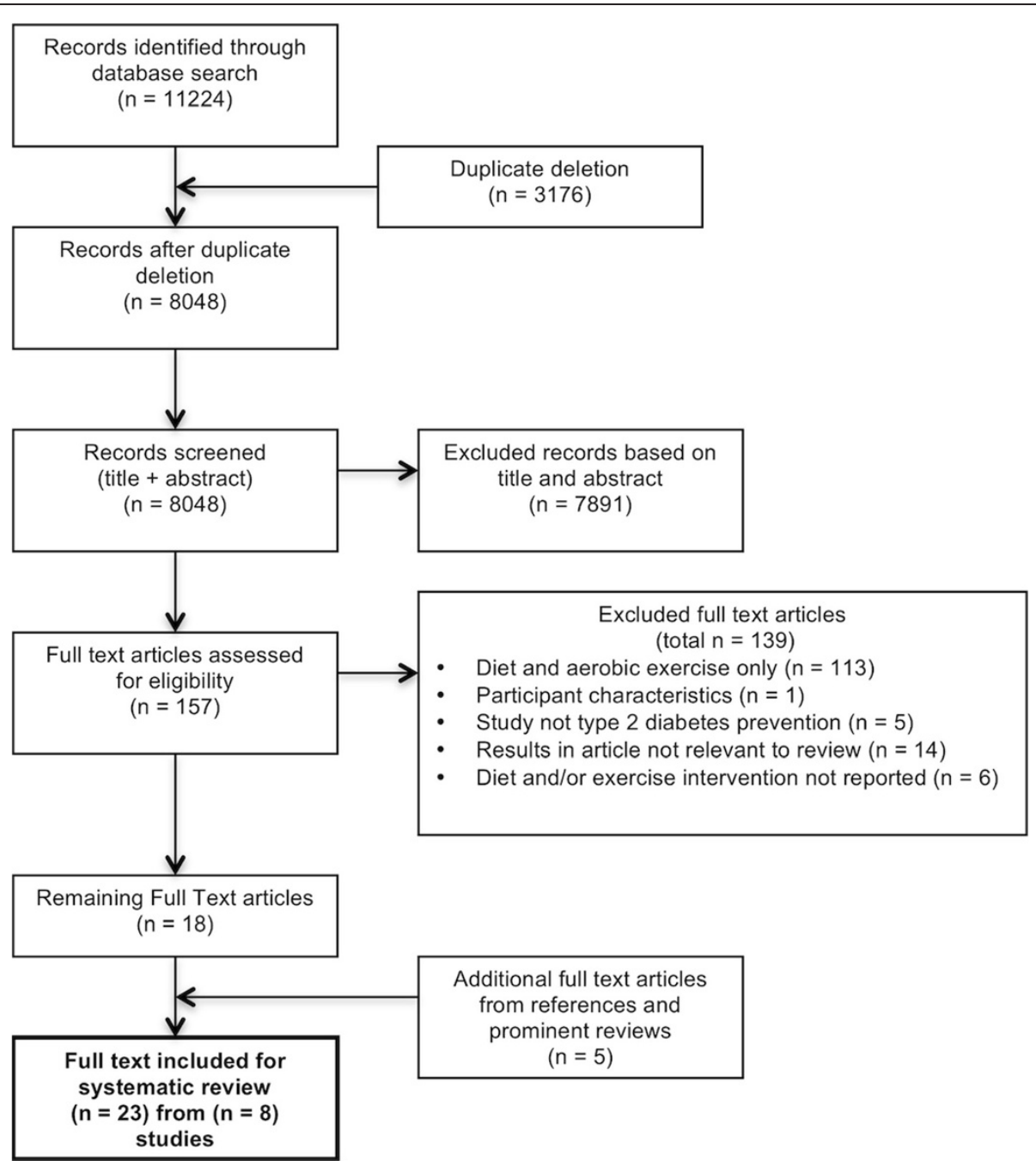

Figure 1 PRISMA flow diagram of study selection. Describes the process of article searching, exclusion (with reasons) and selection of studies of systematic review and meta-analyses. 
Table 1 Risk of bias analysis for randomized studies

\begin{tabular}{|c|c|c|c|c|c|c|c|c|c|c|c|}
\hline $\begin{array}{l}\text { Author, year, } \\
\text { Study Name } \\
\text { (SN) }\end{array}$ & $\begin{array}{l}\text { i) Did the study } \\
\text { report a power } \\
\text { calculation and } \\
\text { was the study } \\
\text { adequately } \\
\text { powered } \\
\text { to detect } \\
\text { intervention } \\
\text { effects? }\end{array}$ & $\begin{array}{l}\text { ii) Was the } \\
\text { randomization } \\
\text { procedure } \\
\text { adequately } \\
\text { described and } \\
\text { carried out? }\end{array}$ & $\begin{array}{l}\text { iii) Did the } \\
\text { study include } \\
\text { a control group? } \\
\text { (randomized } \\
\text { participants not } \\
\text { a comparison } \\
\text { group) }\end{array}$ & $\begin{array}{l}\text { iv) Did the } \\
\text { study present } \\
\text { baseline } \\
\text { characteristics } \\
\text { separately for } \\
\text { treatment } \\
\text { groups? }\end{array}$ & $\begin{array}{l}\text { v) Did the study } \\
\text { analyses account } \\
\text { for potential } \\
\text { differences at } \\
\text { baseline? }\end{array}$ & $\begin{array}{l}\text { vi) Were the } \\
\text { assessors } \\
\text { blinded to } \\
\text { treatment } \\
\text { allocation } \\
\text { at baseline } \\
\text { and post-test? }\end{array}$ & $\begin{array}{l}\text { vii) Did the } \\
\text { study have } \\
\text { a dropout } \\
\text { of }<20 \% \\
\text { ( }<6 \text { month } \\
\text { follow-up) } \\
\text { or }<30 \% \\
\text { ( }>6 \text { month } \\
\text { follow-up for } \\
\text { the primary } \\
\text { outcome } \\
\text { of weight }\end{array}$ & $\begin{array}{l}\text { vii) Did } \\
\text { the study } \\
\text { use an } \\
\text { intention } \\
\text { to treat } \\
\text { analysis? }\end{array}$ & $\begin{array}{l}\text { ix) Did } \\
\text { the study } \\
\text { report } \\
\text { summary } \\
\text { results } \\
\text { for each } \\
\text { group? }\end{array}$ & $\begin{array}{l}\text { x) Did } \\
\text { the study } \\
\text { report precision } \\
\text { estimates (eg } \\
95 \% \text { confidence } \\
\text { interval) and/ } \\
\text { or effect sizes? }\end{array}$ & Total \\
\hline $\begin{array}{l}\text { Author Burtscher } \\
\text { et al. [35] }\end{array}$ & 0 & 0 & 0 & 1 & 1 & 0 & 0 & 0 & 1 & 0 & 3 \\
\hline $\begin{array}{l}\text { Authors Lindstrom } \\
\text { et al. [44], (Eriksson } \\
\text { et al. [42] } \\
\text { (Laaksonen et al. } \\
\text { [43], Lindstrom et al. } \\
\text { [45], Lindstrom et al. } \\
\text { [46], Tuomilehto } \\
\text { et al. [47], Uusitupa } \\
\text { et al. [48], Uusitupa } \\
\text { et al. [49]) SN: } \\
\text { Finnish DPS }\end{array}$ & 0 & 1 & 1 & 1 & 1 & 0 & 1 & 1 & 1 & 1 & 8 \\
\hline $\begin{array}{l}\text { Author McAuley } \\
\text { et al. [34], (Dale } \\
\text { et al. [33]) }\end{array}$ & 0 & 1 & 1 & 1 & 1 & 1 & 1 & 1 & 1 & 1 & 9 \\
\hline $\begin{array}{l}\text { Authors Page et al. } \\
\text { [50] \& Page } \\
\text { et al. [51] }\end{array}$ & 0 & 1 & 1 & 1 & 0 & 0 & 1 & 0 & 1 & 0 & 5 \\
\hline $\begin{array}{l}\text { Author Payne } \\
\text { et al. [41] }\end{array}$ & 0 & 0 & 0 & 0 & 1 & 0 & 1 & 1 & 0 & 1 & 4 \\
\hline $\begin{array}{l}\text { Authors Roumen } \\
\text { et al. [39], } \\
\text { (Corpeleijn et al. } \\
\text { [36], Mensink et al. } \\
\text { [37], Mensink [38], } \\
\text { Roumen et al. [40]) } \\
\text { SN: The SLIM study }\end{array}$ & 1 & 1 & 1 & 1 & 1 & 1 & 1 & 1 & 1 & 1 & 10 \\
\hline $\begin{array}{l}\text { Authors Villareal } \\
\text { [29,31], (Villareal } \\
\text { et al. [30], Villareal } \\
[29,31])\end{array}$ & 0 & 1 & 1 & 1 & 1 & 1 & 1 & 1 & 1 & 1 & 9 \\
\hline
\end{tabular}


respectively. $\mathrm{HbA}_{1 \mathrm{C}}$ was reported in two RCTs (Additional file 3). The Finish DPS [42-49] intervention group had a significant reduction compared to controls $(\mathrm{P}=0.002)$ at three years, whereas the SLIM study [36-40] reported no difference between groups $(\mathrm{P}=0.838)$ at three years.

\section{Exercise outcomes}

Physical activity and/or physical fitness outcomes were questionnaire [29-31,41-49] or exercise testing [29-31,33-40,50,51] based (Additional file 3). Aerobic exercise outcomes were reported in five of the eight studies. McAuley et al. [34] and Dale et al. [33] predicted aerobic capacity $\left(\mathrm{VO}_{2 \max }\right)$ from performance in a sub-maximal walking test (modified Bruce protocol). The intensive intervention group improved compared to controls $(\mathrm{P}=0.02)$ whereas the modest intervention group did not $(\mathrm{P}=0.94)$. In the SLIM study [36-40] aerobic capacity $\left(\mathrm{VO}_{2 \max }\right)$ was assessed using an incremental exhaustive cycle ergometer test. At three years, the intervention group improved their aerobic capacity compared to controls $(\mathrm{P}=0.009)$. At 26 weeks, Villareal et al. [29-31] reported the intervention group $\mathrm{VO}_{2 \text { peak }}$ had improved compared to the controls $(\mathrm{P}=$ 0.02). Page et al. [50,51] measured aerobic capacity $\left(\mathrm{VO}_{2 \max }\right)$ using maximal cycle ergometry. The 'healthy living' intervention group improved aerobic capacity $(\mathrm{P}<0.05)$ whereas the controls did not change ( $\mathrm{P}$ value not reported) at six months. Burtscher et al. [35] reported a pre-post increase in maximum metabolic equivalents (METs max $_{\text {max }}$ ) for their 'counseling + supervised exercise' group after one year, which differed $(\mathrm{P}=0.01)$ to the 'counseling only' group.

Only one of the eight studies measured improvements in muscular strength or performance (Additional file 3). Villareal et al. [29-31] reported significant improvements in knee extension $(\mathrm{P}=0.04)$ and knee flexion $(\mathrm{P}=0.008)$ for the intervention group versus controls after 26 weeks.

No studies used objective measures (e.g., pedometers or accelerometers) to assess physical activity. Selfreported physical activity was presented in three studies (Additional file 3). The Finnish DPS [42-49] reported no difference in mean total leisure time physical activity $(\mathrm{P}=0.2415)$, but moderate-vigorous leisure time physical activity increased in the intervention group compared with controls $(\mathrm{P}=0.006)$ at three years (validated selfreport questionnaire). Burtscher et al. [35] reported that duration of physical activity (min.wk ${ }^{-1}$ from log books) during the last three months of intervention in the supervised exercise group was almost double that of the counseling only group ( $\mathrm{P}$ value not reported). Payne et al. [41] reported pre-post intervention increases in physical activity weighted $\min \cdot \mathrm{wk}^{-1}(\mathrm{P}=0.007)$ and sessions.wk ${ }^{-1}(\mathrm{P}=0.004)$ after one year (validated selfreport questionnaire).

\section{Dietary outcomes}

Dietary composition was assessed in six of the eight studies. Total energy intake (E) expressed as kilocalories (kcal) or kilojoules (kJ) per day was reported in five studies (Additional file 3). The Finnish DPS [42-49] reported reductions favoring intervention over controls at three years $(P=0.007)$. McAuley et al. [34] and Dale et al. [33] reported a reduction in energy intake for modest and intensive intervention groups at four months, however only the modest group $(\mathrm{P}=0.005)$ was significantly different to controls. Significant within group pre-post reductions for energy intake were reported by Page et al. $[50,51] \quad(\mathrm{P}<0.01)$ at six months and Payne et al. [41] $(\mathrm{P}<0.001)$ at 12 months. Results for intervention effects on macronutrient composition are provided in Additional file 3.

\section{Type 2 diabetes incidence}

T2DM incidence was only reported in two studies. The Finnish DPS [42-49] reported the cumulative incidence of T2DM after four years was 58\% lower in the intervention group than controls [47]. The SLIM study [36-40] reported cumulative incidence for T2DM after three years of $18 \%(11 / 61)$ for intervention and 32\% (19/60) for the controls (56\% lower for the intervention compared to control).

\section{Synthesis of results}

Meta-analysis of RCTs with outcomes for weight and FPG were conducted. Funnel plots to assess publication bias were not generated as fewer than 10 interventions were included in the meta-analysis [25].

\section{Weight change}

In total, 325 intervention and 290 control participants (total 644) from four studies were included. The interventions were statistically heterogeneous $\left(X^{2}=18.04\right.$, d.f. $\left.=3, \mathrm{P}<0.001, \mathrm{I}^{2}=83 \%\right)$, so the random effects model was used. Meta-analysis (Figure 2) revealed a significant reduction in weight favoring the interventions over controls at the last reported assessment (WMD $-3.79 \mathrm{~kg}$ $[-6.13,-1.46 ; 95 \% \mathrm{CI}], \mathrm{Z}=3.19, \mathrm{P}=0.001)$. The time frame of assessments varied from four to 36 months.

\section{Fasting plasma glucose}

In total, 331 intervention and 307 control participants (total 667) from five studies were included. The interventions were statistically homogenous $\left(x^{2}=3.01\right.$, d.f. $=$ $\left.4, \mathrm{P}=0.56, \mathrm{I}^{2}=0 \%\right)$, so the fixed effects model was used. Meta-analysis (Figure 3) revealed a significant reduction in FPG favoring interventions over controls at the last 


\begin{tabular}{|c|c|c|c|c|c|c|c|c|c|}
\hline Study or Subgroup & $\begin{array}{r}\text { Inten } \\
\text { Mean [kg] }\end{array}$ & $\begin{array}{l}\text { vention } \\
\text { SD [kg] }\end{array}$ & Total & $\begin{array}{r}\text { Co } \\
\text { Mean }[\mathbf{k g}]\end{array}$ & $\begin{array}{l}\text { ontrol } \\
\text { SD [kg] }\end{array}$ & Total & Weight & $\begin{array}{c}\text { Mean Difference } \\
\text { IV, Random, } 95 \% \mathrm{Cl}[\mathrm{kg}]\end{array}$ & $\begin{array}{c}\text { Mean Difference } \\
\text { IV, Random, } 95 \% \mathrm{Cl}[\mathrm{kg}]\end{array}$ \\
\hline Lindstrom et al 2003 & -3.5 & 5.1 & 231 & -0.9 & 5.4 & 203 & $29.9 \%$ & $-2.60[-3.59,-1.61]$ & $=-1$ \\
\hline Macauley et al 2002 & -5.2 & 6 & 25 & -1.3 & 1.7 & 23 & $23.4 \%$ & $-3.90[-6.35,-1.45]$ & $=$ \\
\hline Roumen et al 2008 & -1.08 & 4.3 & 52 & 0.16 & 4.91 & 54 & $26.8 \%$ & $-1.24[-3.00,0.52]$ & - - \\
\hline Villareal et al 2006 & -8.2 & 5.7 & 17 & 0.7 & 2.7 & 10 & $19.9 \%$ & $-8.90[-12.08,-5.72]$ & $\longrightarrow$ \\
\hline Total $(95 \% \mathrm{Cl})$ & & & 325 & & & 290 & $100.0 \%$ & $-3.79[-6.13,-1.46]$ & \\
\hline \multicolumn{9}{|c|}{$\begin{array}{l}\text { Heterogeneity: } \mathrm{Tau}^{2}=4.48 ; \mathrm{Chi}^{2}=18.04, \mathrm{df}=3(\mathrm{P}=0.0004) ; I^{2}=83 \% \\
\text { Test for overall effect: } Z=3.19(\mathrm{P}=0.001)\end{array}$} & $\begin{array}{ccccc}-10 & -5 & 1 & 1 & 1 \\
\text { Favours intervention } & \text { Favours control }\end{array}$ \\
\hline \multicolumn{10}{|c|}{$\begin{array}{l}\text { Figure } \mathbf{2} \text { Forrest plot }- \text { weight loss } \mathbf{( k g )} \text {. Meta-analysis forest plot comparison of weight loss (kg) in randomized controlled trials (intervention } \\
\text { vs control) at the last reported assessment. Tau } \mathbf{2}^{2}-\text { Tau square test; } \mathbf{C h i}^{2}=\text { Chi square test; } \mathbf{d f}=\text { degrees of freedom; } \mathbf{I}^{\mathbf{2}}=\mathbf{I} \text {-squared statistic; } \\
\mathbf{I V}=\text { inverse variance; } \mathbf{Z}=\text { Z-test. }\end{array}$} \\
\hline
\end{tabular}

reported assessment (WMD -0.13 mmol.L ${ }^{-1}[-0.24,-0.02$; $95 \% \mathrm{CI}], \mathrm{Z}=2.42, \mathrm{P}=0.02$ ), with the time frame from four to 36 months.

\section{Discussion}

This systematic review found that multi-component lifestyle interventions incorporating diet + aerobic exercise + RT conducted in at risk or prediabetic adult populations were efficacious for inducing modest weight loss and eliciting small improvements in glycemic control, together with improvements in aerobic fitness and dietary intake. The impact of interventions on muscular fitness and physical activity were not consistently reported, making it difficult to determine the contributions of these components towards improvements in glucose regulation.

\section{Weight change and glucose regulation}

All interventions in this review and the meta-analysis found significant weight loss compared to controls. Importantly the DPP identified weight loss as the dominant predictor of their $58 \%$ reduction in T2DM incidence [52]. However, the effects on glucose regulation were less consistent. Meta-analysis found a small but significant reduction that would be of clinical importance in those with borderline prediabetes. The baseline FPG mean of the combined study population in the metaanalysis $\left(5.6 \mathrm{mmol} . \mathrm{L}^{-1}\right)$ was at the lower limit of the prediabetes range $\left(5.6-6.9 \mathrm{mmol} . \mathrm{L}^{-1}\right)$ [53]. This suggests that scope to improve further was limited in these cohorts, a circumstance which may be common amongst prediabetic individuals who present in clinical settings. Furthermore, the small magnitude of change observed in the meta-analysis for FPG was heavily influenced by the results of the Finnish DPS, which received a $65 \%$ weighting due to its large sample size. The Finnish DPS excluded participants from the study after diagnosis of T2DM. As the majority of those developing T2DM belonged to the control group, this introduces bias, which underestimates the FPG of the control group, leading to an attenuation of the difference between the groups.

\section{Exercise programs and measurement of related outcomes}

The reporting of exercise programs was inconsistent between studies and most studies provided only general descriptions of their exercise programs. For example, "The supervised exercise group has additionally been offered supervised, progressive, individually tailored aerobic exercise programs and circuit-type resistance training sessions for 1 hour twice a week" [35]. This makes it difficult to determine the specific modes of RT exercises that were performed (e.g., body weight, free weights, isometric exercises, isokinetic exercises, resistance band) and the volume (load, repetitions and sets) prescribed. Future studies are recommended to provide more comprehensive descriptions of the exercise programs. Most studies provided supervised individual or group exercise sessions; only one study included a home-based exercise component [41]. This has implications for the feasibility,

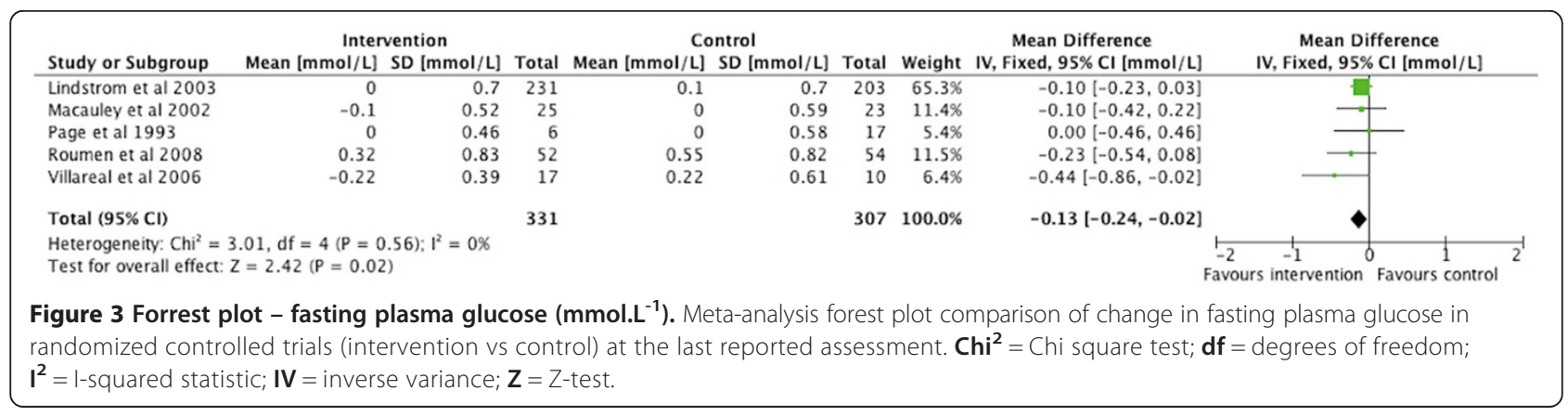


practicalities and dissemination costs of these programs into community and health-care settings, as few health care systems can afford to provide supervision of exercise programs by qualified personnel.

Measurement of exercise-related outcomes was also inconsistent between studies. No studies used objective measures (e.g., pedometers or accelerometers) to assess physical activity, which is a major limitation in existing studies. Physical activity levels as measured by selfreport improved in intervention groups versus controls groups [42-49]. Aerobic exercise tests to measure or predict $\mathrm{VO}_{2 \max }$ were the most widely used fitness indicator, and improvements in aerobic fitness in intervention groups were generally observed [29-31,33,34,36-40]. Only one study measured improvements in muscular strength [29-31], assessing only lower body limb strength using an isokinetic dynamometer. Without evaluation of muscular performance (including upper and lower body muscle groups) it is difficult to determine whether the RT program was adhered to or whether the addition of RT in multicomponent programs contributes to improvements in muscular fitness and glycemic control in prediabetes populations, as has been shown in adults with T2DM [54]. Future studies should provide comprehensive and objective evaluation of the impact on aerobic and muscular fitness.

\section{Type 2 diabetes incidence}

A reduction in T2DM incidence is the goal for all T2DM prevention programs. Of the studies reviewed, incidence of T2DM was only reported in the Finnish DPS and SLIM studies (up to 58\% reduction in T2DM incidence). This finding is of great interest, particularly since the US DPP, which did not prescribe RT as part of their physical activity recommendations, also reported a $58 \%$ reduction in diabetes incidence (after 2.8 years) [5]. This suggests that multi-component T2DM prevention programs that include RT are effective, but whether RT provides benefits additional to dietary and aerobic components requires further investigation.

\section{Features of effective interventions}

Study design and intervention components were heterogeneous amongst the included studies, which may account for some of the variation observed in the outcomes assessed. Design characteristics of studies that achieved significant changes for weight loss and FPG [29-31,33,36-39,41] included: face-to-face intervention delivery mode (individual and/or group), an average of eight contacts per month (including face to face sessions, emails and phone calls), and a minimum of six (preferably 12) months of follow up. Lifestyle intervention characteristics included: 150-210 minutes (3-5 sessions) of aerobic exercise per week; $60-120$ minutes (1-3 sessions) of RT per week; recommendations for a specified macronutrient diet profile, energy restriction for weight loss and setting a weight loss goal of $5-10 \%$.

\section{Sex differences in lifestyle programs}

Of the studies reviewed, $62 \%$ of participants were female. Since there is no reported global difference in gender distribution for diabetes [1], this may indicate that women are more likely to participate in diabetes prevention trials. None of the studies targeted a specific sex or reported their results by sex. Whether males and females benefit equally from these multi-component interventions is not known, but future studies should report their results by sex to reveal any differences that may exist. A recent systematic review [55] argued that sex-specific design features may be important influences on the effectiveness of lifestyle interventions.

\section{Strengths and limitations}

This is the first review to synthesize the evidence of multi-component interventions including diet, aerobic exercise and RT for the prevention of type 2 diabetes. It adhered to the PRISMA statement for the reporting of systematic reviews and meta-analyses; a comprehensive search strategy was performed across multiple databases with no date restrictions; high agreement levels for quality assessments were achieved; and detailed data extraction was performed to allow for comparisons between studies.

The review also has some limitations. Meta-analyses for weight and FPG were based on a small number of studies and the meta-analysis for weight was statistically heterogeneous. The sample for the meta-analyses consisted of $62 \%$ females, which introduces a sex bias. Furthermore the mean age of participants was $54.5 \pm$ 9.7 years and only one study targeted older individuals (>65) [29-31]. This limits the generalizability of the results particularly for older individuals and highlights an evidence gap in the field. Regular resistance training may result in gains or maintenance of muscle mass; consequently weight loss as an outcome by itself would be confounded by the inability to discriminate between loss of fat mass and gains in fat free mass. Future studies need to include more comprehensive assessments of body composition. For the aforementioned reasons results from the original studies and the synthesis of results presented here must be interpreted with caution. Finally, T2DM prevention studies that employed diet + aerobic exercise, but not RT were not eligible, including the highly successful US DPP.

\section{Direction for future research}

This review has highlighted the need for high quality long-term RCTs that assess multi-component lifestyle prevention programs for T2DM. Systematic investigation 
of the benefits of each additional component (diet, aerobic, RT, physical activity) of multi-component lifestyle interventions is also required to provide further support for the current recommendations for T2DM prevention. Future studies should report intervention component adherence and use objective measures to detect changes in muscular fitness, aerobic capacity and physical activity. More comprehensive measures of body composition (e.g., waist circumference, dual $\mathrm{x}$-ray absorptiometry or bioimpedance analysis) should be utilised to determine changes in body composition as a result of multicomponent T2DM prevention programs including RT. Studies exploring interventions tailored specifically for men or women are required to determine any impact on recruitment, retention and efficacy.

\section{Conclusions}

Multi-component lifestyle interventions to prevent T2DM, which include a dietary intervention and both aerobic and resistance exercise training, are modestly effective in inducing weight loss, improving impaired fasting glucose, improving glucose tolerance and improving dietary and exercise outcomes in at risk and prediabetic adult populations. These results support the current exercise guidelines for the inclusion of RT in T2DM prevention. Further research is required to determine the long-term efficacy of multi-component interventions on T2DM prevention and changes in biomarkers of risk and the specific contributions of each intervention component to these outcomes.

\section{Additional files}

Additional file 1: Risk of bias assessment explanation. 10-item risk of bias assessment criteria and an explanation of the scoring details for each item.

Additional file 2: Characteristics of included studies.

Additional file 3: Results of included studies.

\section{Competing interests}

The authors declare that they have no competing interests.

\section{Authors' contributions}

EA was chiefly responsible for data acquisition, analysis and interpretation, as well as drafting the manuscript. All other authors (PM, CC, RP, RC) were responsible for conception and design, data interpretation, revisions, and final approval of the article.

\section{Acknowledgments}

The authors wish to acknowledge Debbie Booth, Simon Harries and Myles Young for their assistance in the preparation of this manuscript. The authors received no funding for this work.

\section{Author details}

${ }^{1}$ Priority Research Centre for Physical Activity and Nutrition, University of Newcastle, Callaghan Campus, University Dr, Callaghan, NSW 2308, Australia. ${ }^{2} S c h o o l$ of Biomedical Sciences and Pharmacy, Faculty of Health, University of Newcastle, Callaghan Campus, University Dr, Callaghan, NSW 2308, Australia. ${ }^{3}$ School of Education, Faculty of Education and Arts, University of
Newcastle, Callaghan Campus, University Dr, Callaghan, NSW 2308, Australia. ${ }^{4}$ School of Health Sciences, Faculty of Health, University of Newcastle, Callaghan Campus, University Dr, Callaghan, NSW 2308, Australia.

Received: 12 July 2013 Accepted: 10 January 2014

Published: 15 January 2014

\section{References}

1. International DF: IDF Diabetes Atlas 6th edn. Brussels, Belgium: International Diabetes Federation; 2013.

2. Barengo NC, Tuomilehto J: Diabetes: exercise benefits in type 2 diabetes mellitus. Nat Rev Endocrinol 2012, 8:635-636.

3. Colberg SR, Sigal RJ, Fernhall B, Regensteiner JG, Blissmer BJ, Rubin RR, Chasan-Taber L, Albright AL, Braun B: Exercise and type 2 diabetes: the American College of Sports Medicine and the American Diabetes Association: joint position statement executive summary. Diabetes Care 2010, 33:2692-2696.

4. Bray GA, Culbert IW, Champagne CM, Dawson L, Eberhardt B, Greenway FL, Guillory FG, Hebert AA, Jeffirs ML, Kennedy BM, et al: The diabetes prevention program - design and methods for a clinical trial in the prevention of type 2 diabetes. Diabetes Care 1999, 22:623-634.

5. Knowler WC, Barrett-Connor E, Fowler SE, Hamman RF, Lachin JM, Walker EA, Nathan DM: Diabetes prevention program Res G: reduction in the incidence of type 2 diabetes with lifestyle intervention or metformin N Engl J Med 2002, 346:393-403.

6. Black LE, Swan PD, Alvar BA: Effects of intensity and volume on insulin sensitivity during acute bouts of resistance training. J Strength Cond Res 2010, 24:1109-1116.

7. Ibanez J, Izquierdo M, Arguelles I, Forga L, Larrion JL, Garcia-Unciti M, Idoate F, Gorostiaga EM: Twice-weekly progressive resistance training decreases abdominal fat and improves insulin sensitivity in older men with type 2 diabetes. Diabetes Care 2005, 28:662-667.

8. Baldi JC, Snowling N: Resistance training improves glycaemic control in obese type 2 diabetic men. Int I Sports Med 2003, 24:419-423.

9. Castaneda C, Layne JE, Munoz-Orians L, Gordon PL, Walsmith J, Foldvari M, Roubenoff $\mathrm{R}$, Tucker KL, Nelson ME: A randomized controlled trial of resistance exercise training to improve glycemic control in older adults with type 2 diabetes. Diabetes Care 2002, 25:2335-2341.

10. Dunstan DW, Daly RM, Owen N, Jolley D, De Courten M, Shaw J, Zimmet P: High-intensity resistance training improves glycemic control in older patients with type 2 diabetes. Diabetes Care 2002, 25:1729-1736.

11. Dunstan DW, Puddey IB, Beilin L, Burke V, Morton AR, Stanton KG: Effects of a short-term circuit weight training program on glycaemic control in NIDDM. Diabetes Res Clin Pract 1998, 40:53-61

12. Bweir S, Al-Jarrah M, Almalty AM, Maayah M, Smirnova IV, Novikova L, Stehno-Bittel L: Resistance exercise training lowers $\mathrm{HbA1c}$ more than aerobic training in adults with type 2 diabetes. Diabetol Metab Syndr 2009, 1:27.

13. Honkola A, Forsen T, Eriksson J: Resistance training improves the metabolic profile in individuals with type 2 diabetes. Acta Diabetol 1997 34:245-248.

14. Ishii T, Yamakita T, Sato T, Tanaka S, Fujii S: Resistance training improves insulin sensitivity in NIDDM subjects without altering maximal oxygen uptake. Diabetes Care 1998, 21:1353-1355.

15. Umpierre D, Ribeiro PA, Kramer CK, Leitao CB, Zucatti AT, Azevedo MJ, Gross $J$, Ribeiro JP, Schaan BD: Physical activity advice only or structured exercise training and association with HbA1c levels in type 2 diabetes: a systematic review and meta-analysis. JAMA 2011, 305:1790-1799.

16. Church TS, Blair SN, Cocreham S, Johannsen N, Johnson W, Kramer K, Mikus CR, Myers V, Nauta M, Rodarte RQ, et al: Effects of aerobic and resistance training on hemoglobin A1c levels in patients with type 2 diabetes: a randomized controlled trial. JAMA 2010, 304:2253-2262.

17. Ballor DL, Poehlman ET: Exercise-training enhances fat-free mass preservation during diet-induced weight loss: a meta-analytical finding. Int J Obes Relat Metab Disord 1994, 18:35-40.

18. Sweeney ME, Hill JO, Heller PA, Baney R, DiGirolamo M: Severe vs moderate energy restriction with and without exercise in the treatment of obesity: efficiency of weight loss. Am J Clin Nutr 1993, 57:127-134.

19. Hordern MD, Dunstan DW, Prins JB, Baker MK, Singh MA, Coombes JS: Exercise prescription for patients with type 2 diabetes and pre-diabetes: 
a position statement from Exercise and Sport Science Australia. J Sci Med Sport 2012, 15:25-31.

20. Snowling NJ, Hopkins WG: Effects of different modes of exercise training on glucose control and risk factors for complications in type 2 diabetic patients: a meta-analysis. Diabetes Care 2006, 29:2518-2527.

21. Sigal RJ, Kenny GP, Boule NG, Wells GA, Prud'homme D, Fortier M, Reid RD, Tulloch $H$, Coyle D, Phillips P, et al: Effects of aerobic training, resistance training, or both on glycemic control in type 2 diabetes: a randomized trial. Ann Intern Med 2007, 147:357-369.

22. Grontved A, Rimm EB, Willett WC, Andersen LB, Hu FB: A prospective study of weight training and risk of type 2 diabetes mellitus in men. Arch Intern Med 2012, 172(17):1306-1312.

23. Cuff DJ, Meneilly GS, Martin A, Ignaszewski A, Tildesley HD, Frohlich JJ: Effective exercise modality to reduce insulin resistance in women with type 2 diabetes. Diabetes Care 2003, 26:2977-2982.

24. Moher D, Liberati A, Tetzlaff J, Altman DG: Preferred reporting items for systematic reviews and meta-analyses: the PRISMA statement. PloS Med 2009, 6(7):e1000097.

25. Higgins J, Green S: Cochrane Handbook for Systematic Reviews of Interventions Version 5.0.2. Cochrane Collab 2009.

26. Moher D, Schulz KF, Altman DG: The CONSORT statement: revised recommendations for improving the quality of reports of parallel group randomized trials. BMC Med Res Methodol 2001, 1:2.

27. Van Sluijs EM, Kriemler S, McMinn AM: The effect of community and family interventions on young people's physical activity levels: a review of reviews and updated systematic review. Br J Sports Med 2011, 45:914-922.

28. Cliff DP, Okely AD, Morgan PJ, Jones RA, Steele JR: The impact of child and adolescent obesity treatment interventions on physical activity: a systematic review. Obes Rev 2010, 11:516-530.

29. Villareal DT, Banks M, Sinacore DR, Siener C, Klein S: Effect of weight loss and exercise on frailty in obese older adults. Arch Intern Med 2006, 166:860-866.

30. Villareal DT, Banks MR, Patterson BW, Polonsky KS, Klein S: Weight loss therapy improves pancreatic endocrine function in obese older adults. Obesity (Silver Spring) 2008, 16:1349-1354.

31. Villareal DT, Miller BV 3rd, Banks M, Fontana L, Sinacore DR, Klein S: Effect of lifestyle intervention on metabolic coronary heart disease risk factors in obese older adults. Am J Clin Nutr 2006, 84:1317-1323.

32. Bersoux S, Asbury KL, Cook CB, Verheijde JL, Larson MH, Aponte-Furlow RT, Flatten SS, Hooley SA, LaRosa CS, Seifert KM, et al: An outpatient-based clinical program for type 2 diabetes prevention. Endocr Pract 2010, 16:21-29.

33. Dale KS, Mann Jl, McAuley KA, Williams SM, Farmer VL: Sustainability of lifestyle changes following an intensive lifestyle intervention in insulin resistant adults: follow-up at 2-years. Asia Pac J Clin Nutr 2009, 18:114-120.

34. McAuley KA, Williams SM, Mann Jl, Goulding A, Chisholm A, Wilson N, Story G, McLay RT, Harper MJ, Jones IE: Intensive lifestyle changes are necessary to improve insulin sensitivity: a randomized controlled trial. Diabetes Care 2002, 25:445-452.

35. Burtscher M, Gatterer H, Kunczicky H, Brandstatter E, Ulmer H: Supervised exercise in patients with impaired fasting glucose: impact on exercise capacity. Clin J Sport Med 2009, 19:394-398.

36. Corpeleijn E, Feskens EJM, Jansen E, Mensink M, Saris WHM, De Bruin TWA, Blaak EE: Improvements in glucose tolerance and insulin sensitivity after lifestyle intervention are related to changes in serum fatty acid profile and desaturase activities: the SLIM study. Diabetologia 2006, 49:2392-2401.

37. Mensink M, Blaak EE, Corpeleijn E, Saris WH, De Bruin TW, Feskens EJ: Lifestyle intervention according to general recommendations improves glucose tolerance. Obes Res 2003, 11:1588-1596.

38. Mensink M, Corpeleijn E, Feskens EJM, Kruijshoop M, Saris WHM, De Bruin TWA, Blaak EE: Study on lifestyle-intervention and impaired glucose tolerance Maastricht (SLIM): design and screening results. Diabetes Res Clin Pract 2003, 61:49-58.

39. Roumen C, Corpeleijn E, Feskens EJM, Mensink M, Saris WHM, Blaak EE Impact of 3-year lifestyle intervention on postprandial glucose metabolism: the SLIM study. Diabet Med 2008, 25:597-605.

40. Roumen C, Feskens EJM, Corpeleijn E, Mensink M, Saris WHM, Blaak EE: Predictors of lifestyle intervention outcome and dropout: the SLIM study. Eur J Clin Nutr 2011, 65:1141-1147.

41. Payne WR, Walsh KJ, Harvey JT, Livy MF, McKenzie KJ, Donaldson A, Atkinson MG, Keogh JB, Moss RS, Dunstan DW, Hubbard WA: Effect of a low-resource-intensive lifestyle modification program incorporating gymnasium-based and home-based resistance training on type 2 diabetes risk in Australian adults. Diabetes Care 2008, 31:2244-2250.

42. Eriksson J, Lindstrom J, Valle T, Aunola S, Hamalainen H, llanne-Parikka P, Keinanen-Kiukaanniemi S, Laakso M, Lauhkonen M, Lehto P, et al: Prevention of Type II diabetes in subjects with impaired glucose tolerance: The Diabetes Prevention Study (DPS) in Finland. Study design and 1-year interim report on the feasibility of the lifestyle intervention programme. Diabetologia 1999, 42:793-801.

43. Laaksonen DE, Lindstrom J, Lakka TA, Eriksson JG, Niskanen L, Wikstrom K, Aunola S, Keinanen-Kiukaanniemi S, Laakso M, Valle T, et al: Physical activity in the prevention of type 2 diabetes: the Finnish diabetes prevention study. Diabetes 2005, 54:158-165.

44. Lindstrom J, Eriksson JG, Valle TT, Aunola S, Cepaitis Z, Hakumaki M, Hamalainen H, Ilanne-Parikka P, Keinanen-Kiukaanniemi S, Laakso M, et al: Prevention of diabetes mellitus in subjects with impaired glucose tolerance in the Finnish Diabetes Prevention Study: results from a randomized clinical trial. J Am Soc Nephrol 2003, 14:S108-S113.

45. Lindstrom J, Ilanne-Parikka P, Peltonen M, Aunola S, Eriksson JG, Hemio K, Hamalainen H, Harkonen P, Keinanen-Kiukaanniemi S, Laakso M, et al: Sustained reduction in the incidence of type 2 diabetes by lifestyle intervention: follow-up of the Finnish Diabetes Prevention Study. Lancet 2006, 368:1673-1679.

46. Lindstrom J, Louheranta A, Mannelin M, Rastas M, Salminen V, Eriksson J, Uusitupa M, Tuomilehto J: The Finnish Diabetes Prevention Study (DPS): Lifestyle intervention and 3-year results on diet and physical activity. Diabetes Care 2003, 26:3230-3236.

47. Tuomilehto J, Lindstrom J, Eriksson JG, Valle TT, Hamalainen H, llanne-Parikka P, Keinanen-Kiukaanniemi S, Laakso M, Louheranta A, Rastas M, et al: Prevention of type 2 diabetes mellitus by changes in lifestyle among subjects with impaired glucose tolerance. N Engl J Med 2001, 344:1343-1350.

48. Uusitupa M, Lindi V, Louheranta A, Salopuro T, Lindstrom J, Tuomilehto J, Finnish Diabet Prevention S: Long-term improvement in insulin sensitivity by changing lifestyles of people with impaired glucose tolerance - 4-year results from the Finnish diabetes prevention study. Diabetes 2003, 52:2532-2538.

49. Uusitupa M, Louheranta A, Lindstrom J, Valle T, Sundvall J, Eriksson J, Tuomilehto J: The Finnish Diabetes Prevention Study. Br J Nutr 2000, 83(Suppl 1):S137-S142.

50. Page RC, Harnden KE, Walravens NK, Onslow C, Sutton P, Levy JC, Hockaday DT, Turner RC: 'Healthy living' and sulphonylurea therapy have different effects on glucose tolerance and risk factors for vascular disease in subjects with impaired glucose tolerance. Q J Med 1993, 86:145-154

51. Page RCL, Harnden KE, Cook JTE, Turner RC: Can life-styles of subjects with impaired glucose tolerance be changed? A feasibility study. Diabet Med 1992, 9(6):562-566.

52. Hamman RF, Wing RR, Edelstein SL, Lachin JM, Bray GA, Delahanty L, Hoskin M, Kriska AM, Mayer-Davis EJ, Pi-Sunyer X, et al: Effect of weight loss with lifestyle intervention on risk of diabetes. Diabetes Care 2006, 29:2102-2107.

53. American Diabetes A: Diagnosis and classification of diabetes mellitus. Diabetes Care 2010, 33(Suppl 1):S62-S69.

54. Eves ND, Plotnikoff RC: Resistance training and type 2 diabetes: Considerations for implementation at the population level. Diabetes Care 2006, 29:1933-1941.

55. Lovejoy JC, Sainsbury A: Sex differences in obesity and the regulation of energy homeostasis. Obes Rev 2009, 10:154-167.

doi:10.1186/1479-5868-11-2

Cite this article as: Aguiar et al.: Efficacy of interventions that include diet, aerobic and resistance training components for type 2 diabetes prevention: a systematic review with meta-analysis. International Journal of Behavioral Nutrition and Physical Activity 2014 11:2. 